\title{
Migration: Epidemic of Mental Disorders Caused by Global Warming and Inequality
}

\author{
Robert Skopec* \\ Researcher-analyst, Slovakia
}

Submission: November 21, 2018; Published: January 22, 2019

"Corresponding author: Robert Skopec, Researcher-analyst, Dubnik, Slovakia

\begin{abstract}
Rising global temperatures may be driving up rates of mental illness as well, a new study suggests. Last year was the third hottest on record, and 2016 was the hottest ever. And more people are struggling with mental health issues in the US now than any other time in the nation's history. Superior predatory skills led to the evolutionary triumph of jawed vertebrates. However, the mechanisms by which the vertebrate brain controls predation remain largely unknown. Here, we reveal a critical role for the central nucleus of the amygdala in predatory hunting. Both optogenetic and chemogenetic stimulation of central amygdala of mice elicited predatory-like attacks upon both insect and artificial prey. Coordinated control of cervical and mandibular musculatures, which is necessary for accurately positioning lethal bites on prey, was mediated by a central amygdala projection to the reticular formation in the brainstem.
\end{abstract}

Keywords: Migration; Epidemic; Mental disorders; Global warming; Economic inequality; Projections; Midbrain; Periaqueductal gray mater; Predatory-like attacks; Central amygdala; Reticular formation; Brainstem

Abbreviations: EU: European Union; WHO: World Health Organization; GWAS: Genomic Scale; ADHD: Attention Deficit Hyperactivity Disorder; MLR: Mesencephalic Locomotor Region; CeA: Central Amygdala

\section{Introduction}

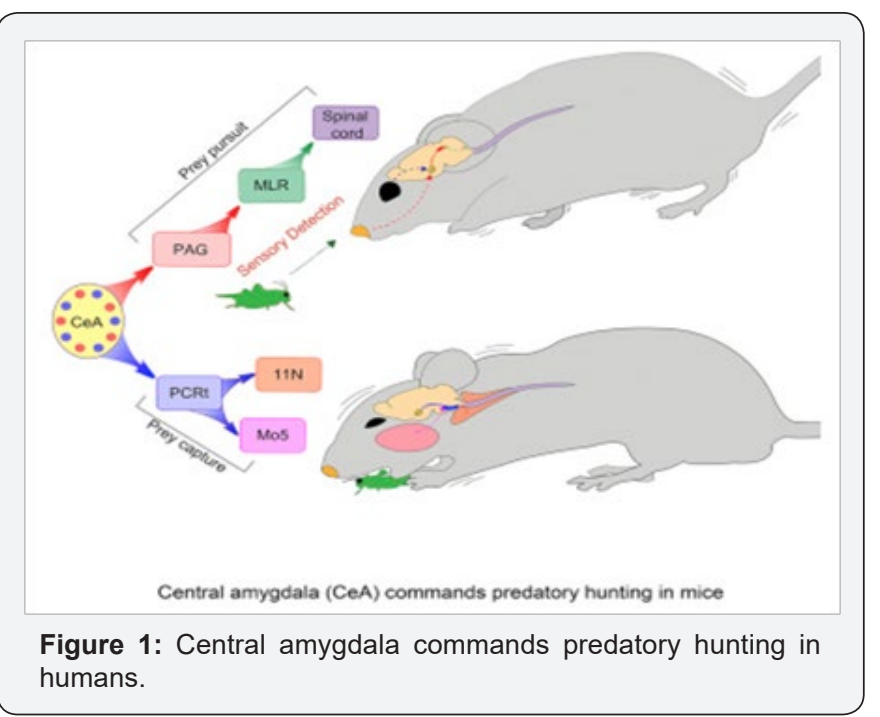

Prey pursuit was mediated by projections to the midbrain periaqueductal gray matter. Targeted lesions to these two pathways separately disrupted biting attacks upon prey versus the initiation of prey pursuit. Our findings delineate a neural network that integrates distinct behavioral modules and suggest that central amygdala neurons instruct predatory hunting across jawed vertebrates (Figure 1).

The Central Nucleus of the Amygdala Activates Craniofacial Musculatures and Promotes Predatory Hunting. Restricted transfection of the light-sensitive depolarizing Channelrhodopsin2 (ChR2) to the central nucleus of the amygdala (CeA) was achieved via stereotaxic injections of the Cre-inducible viral construct AAV-EF1a-DIO-hChR2(H134R)EYFP into the CeA of VGat-ires-Cre mice.

Central Amygdala Activation Did Not Induce Attacks on Conspecifics, Greater Food Intake, or Anxiety-like Behaviors. We failed to observe any occurrences of attacks on conspecifics upon CeA activation, ruling out nonspecific aggression. Also, laser activation did not increase total ingestion of either of two types of food pellets presented, ruling out laser-induced physiological need. Consistently, both chemo genetic activation and inhibition of CeA failed to alter food intake.

Changes in Central Amygdala Neuronal Activity Preceded Prey Capturing. In order to evaluate the behavior of CeA neuronal 
populations during active hunting, we performed electromyogram monitoring of the masseter muscle concomitantly to array neuronal recordings. Principal component analyses of the neuronal data revealed that $\sim 40 \%$ of the recorded neurons increased activity during insect hunting, with hunting-excited CeA neurons maintaining activity levels throughout prey pursuit.

The Central Nucleus of the Amygdala Controls CervicalMandibular Systems by Acting on Inhibitory Interneurons of the Parvocellular Reticular Formation. The Parvocellular Reticular Formation Contains Both Mandibular and Cervical Premotor Neurons. We investigated in greater depth the reticular circuitry mediating CeA control over craniofacial musculatures. Only PCRt-and to a lesser extent the immediately adjacent intermediate reticular nucleus-was found to contain premotor neurons to both Mo5 and 11N. Moreover, VGat neurons in PCRt directly targeted these motor nuclei.

Inhibitory Interneurons in PCRt Bi-directionally Control Mandibular and Cervical Musculatures. We used optogenetics to probe the function of excitatory and inhibitory PCRt populations and $4 \mathrm{~B}$ and N-S4R. In hungry mice offered food pellets, activation of PCRt VGat-positive neurons produced a rapid arrest in oromotor activity, which was immediately resumed upon laser deactivation.

Inhibitory Neurons in PCRt Mediate the Delivery of Killing Bites but Not Prey Pursuit. Based on the above, we reasoned that both optical and tonic depolarization of PCRt VGat neurons should attenuate the potential for mice to successfully hunt insect prey. Activating designer receptors specifically in PCRt VGat neurons completely suppressed the ability to kill and consume crickets.

Central Amygdala Projections to the Periaqued uctal Gray Matter Control Prey Pursuit. CeA $\rightarrow$ PAG optical activation enhanced predatory hunting. Specifically, CeA $\rightarrow$ PAG optical activation increased pursuit velocities and shortened both latency to pursue and overall hunting duration. To counter the inhibitory effects of CeA on PAG neurons, we combined optical stimulation with administration of the designer drug CNO in both VGlut2-ires-Cre and VGat-ires-Cre mice. We found that all of the hunting-promoting effects produced by optical stimulation were annulled by CNO injections in VGlut2-ires-Cre mice. This is consistent with CeA terminals inhibiting their VGlut2-expressing target cells in PAG. CNO treatment in VGat-ires-Cre mice failed to significantly alter optically induced hunting. Finally, and in contrast to $\mathrm{CeA} \rightarrow$ PCRt, CeA $\rightarrow$ PAG activation failed to induce either fictive feeding or approach toward non-food items.

Periaqueductal Gray Matter Projections to the Mesencephalic Locomotor Region Gate Predatory Hunting. We investigated in greater depth the downstream targets of the hunting-controlling PAG[VGlut2+] neurons. Interestingly, analyses of Cre-inducible synaptobrevin expression revealed that VGlut2 neurons in VLPAG/LPAG project densely to dorsolateral midbrain (e.g., pendunculopontine and cuneiform nuclei. These areas are located within the mesencephalic locomotor region ("MLR," Skinner and Garcia-Rill, 1984). As expected, optical activation caused a significant reduction in pursuit velocity, as well as significant increases in both latency to pursue and prey capture duration.

Central Amygdala Controls the Mesencephalic Locomotor Region via the Periaqueductal Gray Matter. Finally, we tested the presumed functionality of the CeA $\rightarrow$ PAG $\rightarrow$ MLR pathway. In the Insame VGat-ires-Cre mice, we transfected the CeA with Creinducible ChR2, implanted optical fibers above CeA terminals in PAG, and transfected the MLR with the non-Cre-dependent excitatory chemogenetic designer receptor.

They hypothesized that administering the designer drug CNO would negate the hunting promoting effects produced by $\mathrm{CeA} \rightarrow$ PAG optical activation. In other words, we predicted that this treatment would mimic the effects of activating PAG VGlut2 neurons during prey pursuit. Consistently, CNO administration completely annulled the hunt-promoting effects of $\mathrm{CeA} \rightarrow$ PAG activation on pursuit latencies and capture duration, albeit having a more modest suppressing effect on velocities. Importantly, all experiments involving the PAG $\rightarrow$ MLR pathway failed to influence performance on open-field tests.

Co-activation of the CeA $\rightarrow$ PCRt and CeA $\rightarrow$ PAG Pathways Is Sufficient to Induce Robust Hunting. From the series of studies above, we inferred that different CeA downstream targets mediate craniofacial control versus prey pursuit. Consistently, dual retrograde tracer injections in PAG and PCRt revealed that CeA neuronal groups projecting to PAG versus PCRt are largely segregated. We then analyzed the effects of activating both pathways simultaneously.

For every degree the globe warms, $2 \%$ more people will have mental health disorders. Last year was the third hottest year on record, and 2016 was the hottest. Rising temperatures have begun to damage societal and physical health in the US as well as the environment. New Massachusetts Institute of Technology and Harvard University research linked natural disasters to a $4 \%$ higher rate of mental illness in the US. These weather events will become more common with global warming. For everyone degree Celsius the temperature rises, mental health issues become 2 percent more common.

Rising global temperatures may be driving up rates of mental illness as well, a new study suggests. Last year was the third hottest on record, and 2016 was the hottest ever. And more people are struggling with mental health issues in the US now than any other time in the nation's history.

New research from Massachusetts Institute of Technology (MIT) and Harvard University suggests that it isn't a coincidence: with every degree (Celsius) the global temperature rises, mental health issues become two percent more common (Figure 2). 


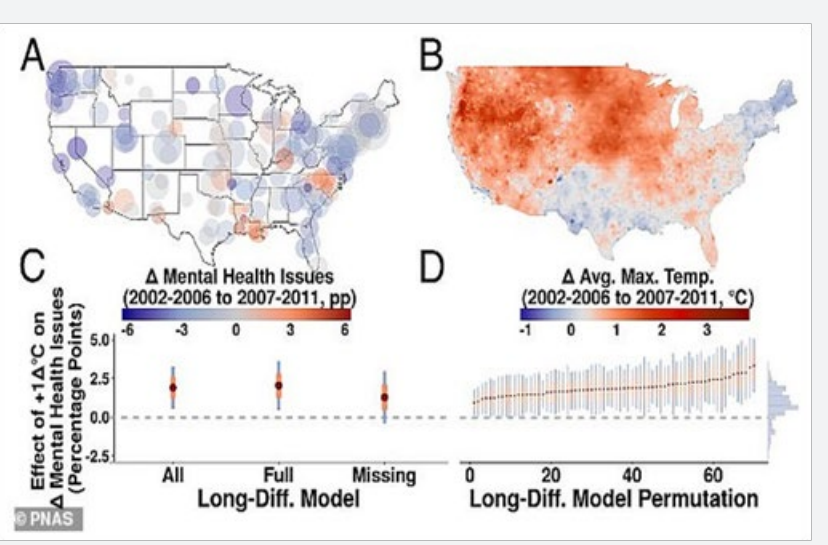

Figure 2: Mental health issues increased in areas hit by natural disasters and those where temperatures rose over time, maps from the new study show.

Mental health issues increased in areas hit by natural disasters and those where temperatures rose over time, maps from the new study show. Every species on the planet is already feeling the effects of global warming. Humans are no exception, but our unique brains suffer unique consequences.

Many studies have shown that, on hotter days, more people wind up in the emergency room, and not just for more obvious problems like heat stroke and dehydration. The number of people making visits for psychological and psychosocial reasons surges as well. People also tend to behave more impulsively and erratically on hotter days, and the heat simply doesn't mix well with some psychiatric drugs.

Earlier this year, Stanford University researchers reported that a single degree Celsius of temperature increase was linked to a higher rate of depressive tweets and an increase in suicides in both the US and Mexico. For the new study, the MIT and Harvard team compared temperature changes and mental health issues, as reported by more than two million people in a number of different contexts across the US. Using more than a decade's worth of data, they examined mental health around the time of single, extreme events, over the period of a month, and over a five-year period.

It didn't matter how long the trajectory of rising temperatures was, in every scenario mental health problem became more prevalent. Unsurprisingly, the most dramatic events came with the most dramatic shifts in mental health.

After Hurricane Katrina in August 2005, reports of mental health issues were four percent higher among those whose homes, loved ones and lives were affected by the storm than among those that lived outside the disaster areas. But even more subtle shifts over the course of a month made mental health issues more likely. During months when the average temperature was over 30 degrees $\mathrm{C}$ - 86 degrees $\mathrm{F}$, mental health issues were 'amplified' by more than one percent, the researchers reported.
And the rain made things worse too. When there was rain for more than 25 out of the 30 (give or take) days of the month, the population was two percent more afflicted by mental health issues. A look at changes over five years helped the scientists get a better idea of how climate change as a long-term phenomenon may change the mental health of people worldwide. With the shift of monthly average temperatures from 25 degrees $\mathrm{C}(77 \mathrm{~F})$ to 30 degrees $\mathrm{C}(86 \mathrm{~F})$ comes a two percent increase in mental health issues Rahal [1].

In the US, about one in every five people has a mental illness issue in a given year. That means that for every degree warmer the globe gets; another 88,000 Americans are liable to develop a mental illness. It isn't clear exactly why natural disasters and changing temperatures have such dastardly effects on mental health, but it becomes increasingly certain that the problem will only spread and intensify.

Warming is likely to amplify the frequency and intensity of natural disasters, which often cause physical injury, psychological trauma infrastructure damage, and societal disruption in affected regions. Gradual changes in climate change are also expected to alter human systems in costly ways, the study authors wrote. While the precise magnitude of these climate-induced adversities is difficult to estimate, the theoretical relationship between climate change and mental health risk is exactly proved.

\section{The Top Rich in Europe and Inequality}

Recent research into the share of wealth owned by the richest households has given us important insights into trends in inequality. This column shows how we can now estimate the share of wealth owned by the richest households in Europe, and how many they numbered, from 1300 to the present day. Throughout this time, the only significant declines in inequality were the result of the Epidemic Black Death and the World Wars.

In the renewed interest in long-term trends in economic inequality, particular attention has been paid to the share of income or wealth earned or owned by the top $1 \%, 5 \%$, or $10 \%$. The share of the richest is both interesting on its own terms (it shows us how 'rich' better-off people actually were), and as an indicator of the overall trends in economic inequality.

There is considerable evidence that the trend in the share that the richest earn or own determines the trend in general economic inequality, for example as it is measured by Gini indexes Atkinson, Alvaredo \& Roine, et al. [2,3] New time series of wealth concentration spanning the 20th and part of the 19th century have recently been produced for some countries Piketty \& Roine et al. [4-6]. This has considerably increased our knowledge of how wealth inequality has changed over time, and in the share of the richest. This research has supplemented existing studies which had covered a few countries or areas only, particularly the UK and the US. 
Now we have comparable data for the preindustrial period. To a significant degree this is due to the ERC-funded project Economic Inequality across Italy and Europe, 13001800 (EINITE). EINITE has collected, systematically and with a uniform methodology, information about long-term trends in wealth inequality, and in the share of the richest, for many ancient Italian states as well as for a few other areas of Europe
Alfani, Ryckbosch \& Alfani et al. [7-10]. Whenever possible EINITE's statistics cover the period from around 1300 to 1800 , and so they allow us to extend the series of the share of wealth owned by the richest by about 500 years. Figure 1 shows the share of wealth of the top $10 \%$ between 1300 and 2010, using Piketty [11] for the post-1800 period.

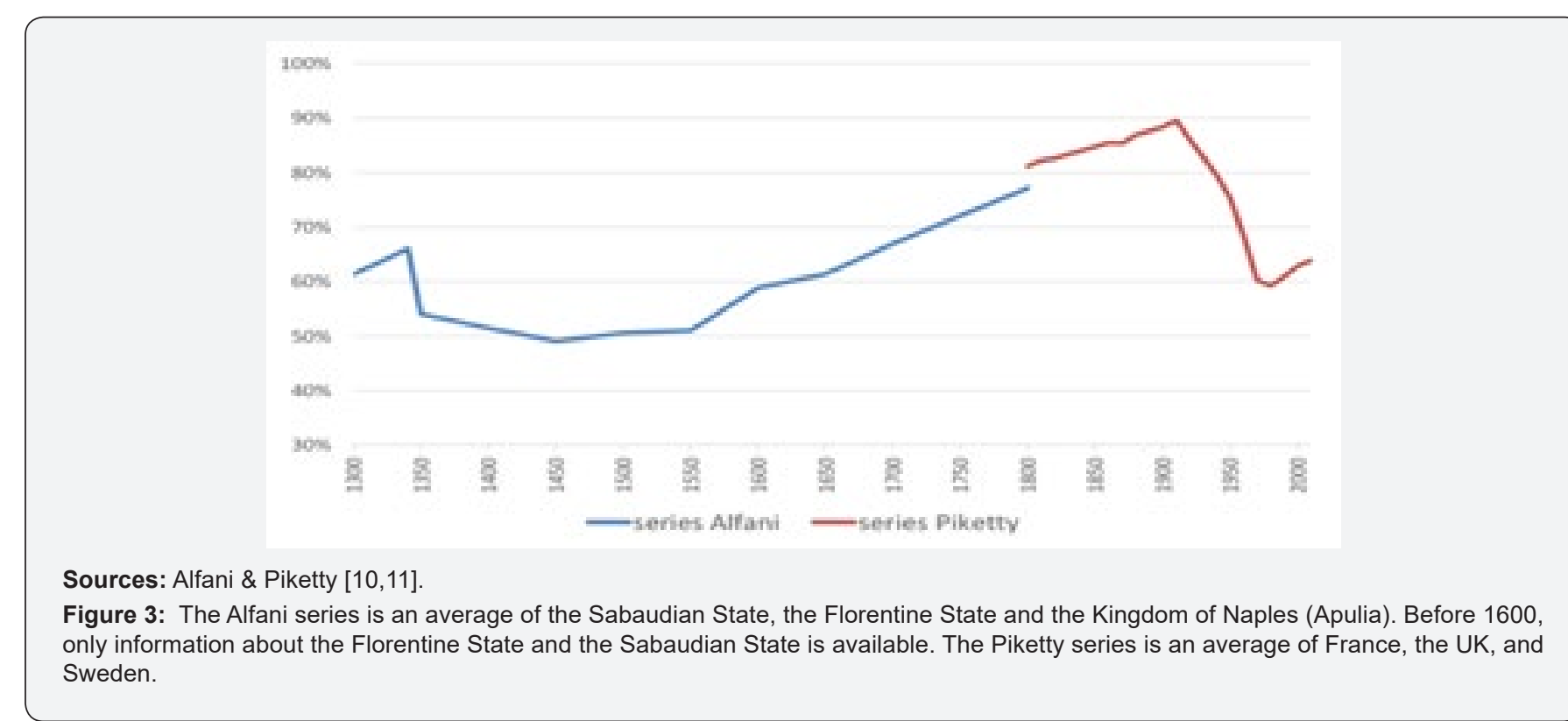

The share of wealth of the richest 10\% in Europe, 1300-2010 (Figure 3):

\section{Extending the Kuznets Curve}

Although the data used for the pre- and post-1800 periods relate to different areas of Europe, there is nevertheless an impressive apparent continuity in the series. Piketty [11] estimated that in 1810 , the richest $10 \%$ of Europeans owned $82 \%$ of the wealth. In a recent comparative article, I found that, in a variety of Italian pre-unification states in 1800 the share owned by the top $10 \%$ was between $70 \%$ and $80 \%$. The estimated average in Figure 1 is $77 \%$.

Remarkably, Piketty's series for 1810-1910 shows the share of the richest growing at almost exactly the same pace as the I calculated for the series between 1550 and 1800. The empirical data therefore strongly supports the view that the left-hand portion of the 'Kuznets curve' - an inverted-U path followed by economic inequality through the industrialization process - can be extended to the left by many centuries, Alfani [7]. We can make this claim even though the underlying causes of the increase in inequality are complex and will need further research to be identified correctly Alfani \& Alfani $[9,10]$.

In the seven centuries recent research covers, across all the territories for which we have data, we find only two phases of significant inequality decline. Both were triggered by catastrophic events: a) The Epidemic Black Death, the most terrible epidemic in human history, affected Europe in 1347-51. Afterwards the richest $10 \%$ lost their grip on between $15 \%$ and $20 \%$ of overall wealth. This was a long-lasting decline in inequality. The richest $10 \%$ recovered their pre-Black Death quota only in the second half of the 17 th century). This decline in the share of the top rich, as well as in overall inequality, was overall inequality, was probably the consequence of two main factors. On one side of the distribution there was an increase in real wages of skilled and unskilled workers. We have evidence for this in many areas of Europe, as described in Pamuk [12]. This helped a larger proportion of the population to gain access to property. On the other side, large patrimonies fragmented due to a mortality crisis which was occurring in the presence of an unmitigated partible inheritance system Alfani [7,13].

b) Shocks occurred between 1914 and 1945 related to the two World Wars, as argued by Piketty 2014, pp. 368-370). The share of wealth owned by the top rich has been growing again since around 1950, and reached $64 \%$ in 2010, but it is still far from the peak of $90 \%$ reached in 1910 . The share of the richest $10 \%$ today is about the same as that in Europe (or at least, Italy) immediately before the Epidemic Black Death.

Additional research would substantiate these empirical similarities. One thing is clear, though: the long-term perspective of recent research requires us to move beyond the characterization 
of inequality time dynamics provided by Kuznets. Milanovic [14] recently argued that long-term trends in inequality could better be described as a succession of Kuznetsian 'waves', while Scheidel [15] proposed that we generalize to an even longer period of human history the levelling ability of epidemic- and war-induced mass mortality. We need more research and more encompassing databases, especially for the preindustrial period, to assess confidently the characteristics, causes and implications of the very long-run tendency for wealth to concentrate in the hands of the few.

\section{How Many Households were Rich?}

New research data allow us to ask many more than "how rich were the rich?" For example, we might wish to know how many were among the rich. This an easy question to ask, but not to answer. We need to find a way to define the 'rich', as distinct from the rest of society. The simplest way of doing this is to give a relative definition of the rich, setting the bar at certain multiplier of the median income or wealth Medeiros et al. [16]. For wealth, a convenient threshold is ten times the median Alfani [17]. If we apply this threshold to the data provided by the EINITE project for a variety of ancient Italian states, we get Figure 2.

The prevalence of the rich in Italy, 1300-1800 ('rich' defined as $1000 \%$ of median wealth) (Figure 4 ):

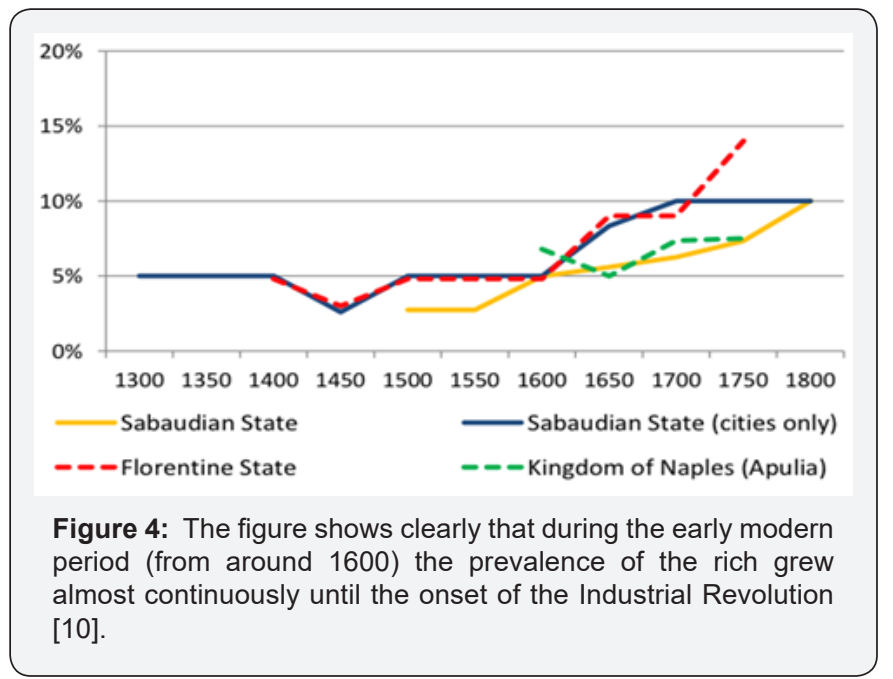

The figure shows clearly that during the early modern period (from around 1600) the prevalence of the rich grew almost continuously until the onset of the Industrial Revolution. The rich made up no more than $5 \%$ of the overall population during the Middle Ages and the first part of the early modern period. By 1800, in the Sabaudian State in north-western Italy, $10 \%$ of the population were rich, and in 1750 in the Florentine State in central Italy, $14 \%$ were rich. This suggests that society was becoming more polarised. Alongside the increase in the share of wealth concentrated among the richest, we see a larger group of people growing ever more distant (in terms of wealth) from the rest of the population Alfani [17].
The relative stability of our indicators during the 14th, 15th and 16th centuries suggests that the Black Death had less effect on the prevalence of the rich than on their wealth. The stability in Figure 2 is, however, at least partly artificial. It is due to the interaction between the components of the aggregate distributions used here. If we focus on specific case studies, we find that in every known case a decline in the prevalence of the rich occurred after the epidemic Alfani [17].

For example, in the Piedmontese city of Cherasco, the rich households made up $4.7 \%$ of the total in 1347 , just before the Black Death. By 1395, just $3.1 \%$ of households were rich. It would be interesting to know how many rich households there were after 1800 , but this seems to be a largely neglected field of enquiry. Knowing this would give us additional insight into how an increasing wealth concentration shaped society. This seems to be one of those cases in which we know more about ancient societies than about recent ones - including the one to which we belong.

\section{Humans and Mice Share a Common Genetic Base of Violent Behavior}

The origins of the violent behavior are multifactorial and respond to the interaction of several factors -- biological, cultural, social, etc. -- which can modify the expression of the human behavior. Now, an international study published in the journal Molecular Psychiatry has identified forty genes related to aggressive behaviour in humans and mice.

Participants in the study, which could contribute to shape future pharmacological targets, are the researchers Bru Cormand and Noèlia Fernàndez Castillo, from the Faculty of Biology and the Institute of Biomedicine of the University of Barcelona (IBUB), the Research Institute Sant Joan de Déu (IRSJD) and the Rare Diseases Networking Biomedical Research Centre (CIBERER). Both are experts in the field of genomic data analysis and genic interaction network. The new study, led by the expert Stephen V. Faraone, from the State University of New York (United States), provides a deeper and integrative view on the genetic basis of aggressiveness and the common functional ways that alter the brain circuit of violent behavior in different species.

On Mice and Humans: Genes, Evolution and Aggressiveness

According to the lecturer Bru Cormand, head of the Research Group on Neurogenetics at the Faculty of Biology of the UB, "aggressive behaviour is a present feature over the biological evolution since it has some benefits for the survival of species (accessing resources, breeding, etc.). In these lines, our study focuses on the biological basis of aggressiveness, i.e. those endogenous factors that tend to show certain antisocial behaviours."

"However -says Cormand- aggressiveness has a significant environmental element, which was not considered in this 
scientific study. Therefore, it would be interesting to combine genetic and environmental data from the same individuals to consider the interactions that can occur between the same risk factors that influence this kind of behaviour."

Humans and mice share a common genetic base regarding violent behaviour, authors note. In particular, they identified forty genes in humans and mice that can lead to a risk of aggressive behaviours "and that take part in biological processes that are related to the development and function of the central nervous system, communication within cells and cellular function maintenance," adds researcher Fernàndez Castillo (IBUBCIBERER-IRSJD). "Some gens are likely to function as important nodes of the genic networks prone to a violent behavior, and those would be probably related to other genes which play a minor role," adds the researcher.

"If any of those central genes is altered, it could affect the other genes and lead to the aggressive phenotype. For instance, RBFOX1 gene, identified in the new study and cited in a previous article by our team (European Neuropsychopharmacology, 2017), regulates the expression of fifteen out of the forty genes that we identified in the study. Another gene we marked -MAOA, which codes a metabolizing enzyme of the serotonin neurotransmission-, is related to drugs used to treat several psychiatric pathologies, sycg as selective inhibitors of serotonin reuptake or SSRIs."

\section{Aggressiveness: from ADHD to Major Depression}

The study reveals a shared genetic base between the aggressiveness in children and adults and the Attention Deficit Hyperactivity Disorder (ADHD), and the aggressiveness in adults and major depression. However, there is no genetic correlation with other psychiatric disorders -schizophrenia, bipolar disorder, autism or post-traumatic stress disorder-, so everything suggests these pathologies would not share risk genetic factors with aggressiveness.

The experimental protocol of the new study combines several analyses evaluating the genetic basis of aggressiveness from different perspectives. Regarding humans, they analyzed several association studies -between patients and healthy volunteers- at a genomic scale (GWAS), to identify risk genetic variants that are common among the general population, as well as transcriptome data showing alterations in the genic expression related to certain aggressive phenotypes. In murine models, researchers studied genes expressed differentially in aggressive animals and non-aggressive animals from the same strain, and other genes that, once they are inactive -in transgenic mice-, form an aggressive phenotype, sometimes related to a broader symptomatology.

Working globally on the involved functional pathways in violent behaviors enabled researchers knowing more about the details of the molecular mechanisms that work behind aggressiveness. "The most relevant verification of the study is that many genes are related to aggressiveness according to the results of very different experimental methodologies, which strengthens the idea of those participating in the behaviour profile," highlight Cormand and Fernàndez Castillo, members of the international multidiscipline consortium Aggress type for the study of biological and environmental causes of aggressiveness.

The UB experts have published several articles shaping candidate genes -in humans, in murine models, zebra fish and in insects- as prone factors to alterations in behavior.

\section{Violence: Government, Communities, and Individuals can Change the Situation Worldwide}

"The 20st century will be remembered as the century of violence. Many people live with it daily and regard it as something consubstantial to the human condition, but it is not so. We can avoid it. Governments, communities and individuals can change the situation," said Nelson Mandela, politician and Nobel Peace Prize awardee in 1993, in the world report on violence and health of the World Health Organization (WHO, 2002). In 2014, the WHO report on the world situation regarding prevention of violence quoted Nelson Mandela's words and called all countries to improve preventive measures against violent behaviours. In this world scenario, facing a problem that affects all the layers of society, scientific research will become more and more important in the knowledge of the basis of antisocial behaviors and the improvement of the prevention of episodes of violence and aggressiveness in the 21st century society Zhang-James et al. [18].

\section{Globalization of Migration and Predator-Like Foreign Policy}

Globalization of Migration lead during last 3 years to big tension in USA and Europe regarding the ways of possible solutions of this new world phenomenon. As we pointed out above, the causes of globalization of migration are multifactorial, including Global Warming, growing Economic Inequality, 4th Industrial Revolution in states and regions, plus the common genetic base of violent behavior, etc. It was also in growing manner leading to new type of approaches in International Relations with more aggressive, Predator-Like Foreign Policy concerning the process of Globalization of Migration. Political leaders of several states are reacting to this new phenomenon with panic reactions in their International Policy. We can see today, that governments of such states like USA, Hungary, Poland, Czech Republic, Croatia, etc., are taking extremely nationalistic, populistic positions in their Foreign Policy against ongoing Globalization of Migration. For example, they are getting off from the process of UN Global Compact on Migration. Similarly they are fighting against common Migration Policy in European Union (EU). Hungary and Czech Republic are going this way despite their experienced big help from the International Community of states decades ago, when they were in big crisis [19]. 
Hungary in the year 1956, and former Czechoslovakia in 1968 had released more than 300000 refugees and migrants each one. Despite this historical solidarity and help of International Community, Hungary and Czech Republic are today going on the way of populistic, Predator-Like Foreign Policy against migration waves, and also against their own political partner states in EU and NATO, which are realizing more human Foreign Policy in the questions of migration. How it was demonstrated during Midterm Elections in November 2018, the same is valid also for the USA in the era under the Presidency of Donald Trump. Recent political leaders of Hungary, Czech Republic, Australia, Bulgaria, Poland, Austria and Croatia have probably forgotten that the European Union was in 20st century created also against the policy of aggressive nationalism and populism. Recent Prime Minister of Hungary Victor Orbán is providing a policy of populism and nationalism similar to the politics of his tragic predecessors between 1914 and 1945, which were lead Hungary into two World Wars: former Prime Minister István Tisza and former Governor Miklós Horthy.

Recently (November 2018) the only real exception from Predator-Like Foreign Policy in Central Europe is Slovakia. Prime Minister of Slovakia Peter Pellegrini is providing more human Foreign Policy concerning UN Global Compact on Migration.

\section{References}

1. Rahhal N (2018) For every degree the globe warms, $2 \%$ more people will have mental health issues, new research warns. Daily Mail.

2. Atkinson AB, Picketty T, Saez E (2011) Top Incomes in the Long Run of History. Journal of Economic Literature 49(1): 3-71.

3. Alvaredo F, Atkinson AB, Picketty T, Saez E (2013) The Top 1 Percent in International and Historical Perspective. Journal of Economic Perspectives 27(3): 3-20.

4. Roine J, Waldenström D (2015) Long Run Trends in the Distribution of Income and Wealth. In: A Atkinson, F. Bourguignon (Eds,) Handbook of Income Distribution, North-Holland, 2.

5. Piketty T, Postel-Vinay G, Rosenthal JL (2006) Wealth Concentration in a Developing Economy: Paris and France, 1807-1994. American Economic Review 96(1): 236-256.

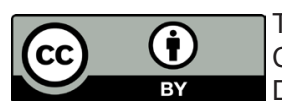

This work is licensed under Creative Commons Attribution 4.0 License DOI: 10.19080/ARGH.2019.12.555831
6. Piketty T (2014) Capital in the Twenty-First Century, Belknap Press of Harvard University Press.

7. Alfani G (2015) Economic Inequality in Northwestern Italy: a LongTerm View (Fourteenth to Eighteenth centuries). Journal of Economic History 75(4): 1058-1096.

8. Alfani G (2017) The rich in historical perspective. Evidence for preindustrial Europe (ca. 1300-1800). Cliometrica 11(3): 321-348.

9. Alfani G, Ryckbosch W (2016) Growing apart in early modern Europe? A comparison of inequality trends in Italy and the Low Countries, 1500-1800. Explorations in Economic History 62: 143-153.

10. Alfani G, Ammannati F (2017) Economic Inequality and Poverty in the Very Long Run: The Case of the Florentine State (late Thirteenth-Early Nineteenth Centuries). Economic History Review.

11. Piketty T, Postel-Vinay G, Rosenthal JL (2014) Inherited vs Self-Made Wealth: Theory and Evidence from a Rentier Society (Paris 18721937). Explorations in Economic History 51: 21-40.

12. Pamuk S (2007) The Black Death and the origins of the 'Great Divergence' across Europe, 1300-1600. European Review of Economic History 11(3): 289-317.

13. Alfani G (2010) The effects of plague on the distribution of property: Ivrea, Northern Italy 1630. Population Studies 64(1): 61-75.

14. Milanovic B (2016) Global Inequality: A New Approach for the Age of Globalization. Harvard University Press.

15. Scheidel W (2017) The Great Leveller: Violence and the Global History of Inequality from the Stone Age to the Present. Oxford University Press.

16. Medeiros M, Ferreira de Souza PHG (2014) The Rich, the Affluent and the Top Incomes: a Literature Review. IRLE Working Paper 105-114.

17. Alfani G (2017) The top rich in Europe in the long run of history (1300 to present day).

18. Zhang-James, Noèlia Fernàndez-Castillo, Jonathan L Hess, Karim Malki, Stephen J Glatt, et al. (2018) An integrated analysis of genes and functional pathways for aggression in human and rodent models. Molecular Psychiatry.

19. Wenfei Han, Ivan E de Araujo (2017) Integrated Control of Predatory Hunting by the Central Nucleus of the Amygdala. Cell 168(1-2): 311324.

\section{Your next submission with JuniperPublishers will reach you the below assets}

- Quality Editorial service

- Swift Peer Review

- Reprints availability

- E-prints Service

- Manuscript Podcast for convenient understanding

- Global attainment for your research

- Manuscript accessibility in different formats

( Pdf, E-pub, Full Text, audio)

- Unceasing customer service

Track the below URL for one-step submission

https://juniperpublishers.com/online-submission.php 